\title{
Determination of parameters for historical British earthquakes
}

\author{
Roger M.W. Musson \\ Global Seismology Group, British Geological Survey, Edinburgh, U.K.
}

\begin{abstract}
Examination of 20th century data from the U.K. shows a good correlation between felt area and instrumental magnitude, producing good magnitude values for historical earthquakes where felt area is known; this is a more reliable method than using $I_{0}$. The equations: $M_{L}=1.03 \log A_{3}-0.19 ; M_{L}=0.92 \log A_{4}+0.71$ give magnitude from areas within isoseismals 3 and 4 MSK. Depths for historical earthquakes have also been obtained using a modification of the well-known Sponheuer method, using the program MACDEP; the regional value for $\alpha$ is 0.003 and depths for events with magnitude above $4 M_{L}$ range from 3 to $25 \mathrm{~km}$.
\end{abstract}

Key words earthquake depth - earthquake magnitude - historical earthquakes

\section{Introduction}

Over the last twelve years much work has been conducted by BGS to research and revise the historical seismicity of the U.K. The results of this research are summed up in a new catalogue of British earthquakes (Musson, 1994). This catalogue contains 502 earthquakes and fulfills two functions: in the first instance it forms a reasonably consistent catalogue of the larger British earthquakes, here defined as events with magnitude greater than or equal to 4.0 $M_{L}$. In the second instance it also contains a large number of smaller earthquakes, particularly those of interest through having been felt. In this paper the techniques used to determine parameters for historical (i.e., non-instrumental) earthquakes are presented and discussed.

Mailing address: Dr. Roger M.W. Musson, Global Seismological Group, British Geological Survey, Murchison House, West Mains Road, Edinburgh EH9 3LA, U.K.; e-mail: R.Musson@bgs.ac.uk

\section{Date}

While superficially this might seem straightforward to determine, in fact there are many pitfalls, and considerable care must be taken. If errors in dates are not spotted, duplicate earthquakes are liable to appear in the catalogue. A common problem is accounts which date earthquakes by the day of the week («last Tuesday»). These are frequently reprinted without correction by newspapers a week after they were written, leading to implied event dates that are a week out. Errors in the year may result from different dating systems; it was usual in the early 18th century to start the new year on 25 March rather than 1 January; thus a date given as 1 March 1727 may be 1728 by modern reckoning. Confusions between Julian and Gregorian calendars must also be guarded against, especially in cases (i) where earthquakes occur round about the time when a transition was being made from old to new style dates, which for Britain is in the 1750 s, or (ii) there are reports from more than one country and the two countries are using different calendars. For medieval and renaissance earthquakes, it is necessary to master the Roman calendar, the Church calendar, and reg- 
nal years. Cheney (1970) is an invaluable guide. Many early British earthquakes are given widely different dates by different sources, apparently due to careless copying. Ambraseys and Melville (1983) have sorted out the tangle for many of these events.

\section{Time}

The practice of accurate time keeping did not exist in Britain until the coming of railways in the $1840 \mathrm{~s}$. Before that, with no calibration of any sort, all time values can only be regarded as approximate. Even as late as 1880 , Dublin time was different from Greenwich time. In the medieval period the value of an hour changed according to the length of time between sunrise and sunset. For early events often the only time indication is a phrase such as «around daybreak». Times for such events can only ever be approximate. The main importance of this parameter is either in distinguishing nocturnal events from those during the day, in that the effects of a nocturnal earthquake will be different (sleepers woken, etc.), or identifying duplicate earthquakes.

\section{Epicentre}

Where epicentres are macroseismically determined, this is done from a combination of: centre of highest isoseismal(s), centre of felt area, position of highest intensities and location of foreshocks/aftershocks. The use of macroseismic data to determine epicentres has been investigated in more detail by Cecić et al. (1996).

Where events are relatively deep, the absence of concentrated high intensities can lead to some uncertainty in the epicentral position. In this case the occurrence of minor associated shocks can be helpful; being smaller, these are less ambiguously located. An example is the 16 August 1934 Torridon earthquake, which has been located largely on the basis of the protracted aftershock sequence.

There is a problem as to when the evidence is insufficient to assign a meaningful epicentre.
To give epicentral co-ordinates to an event on the basis of a report that the earthquake was «felt all over England», coupled with perhaps one named location of damage to a single building (usually a cathedral); would be dangerously misleading. How much uncertainty is allowable is a subjective decision; thus in the catalogue under discussion no epicentral coordinates have been given for the 26 January 1165 earthquake which seems to have had an epicentre in or near East Anglia, but an estimated epicentre has been given to the West Scotland earthquake of 23 April 1817 which is almost as poorly determined, with data points only at the fringe of the felt area. In dealing with medieval earthquakes where the data are very poor, it is important to resist the temptation to «improve» the data by making optimistic assumptions that one can deduce where the earthquake was and was not felt by the location or absence of entries in various chronicles. Unless the chronicle actually states that the earthquake was felt at that town or monastery, an entry may only represent news heard second-hand (for example, see Guidoboni, 1983).

In dealing with poorly-located events it can be tempting to attribute them to known sources of seismicity in the same general area. In many cases, the assumption will be correct, but there is the danger that the seismicity will be portrayed as more clustered than it really is. An extreme example is the mislocation of the 15 August 1926 Ludlow earthquake by Davison (1926) to Ross-on-Wye, $35 \mathrm{~km}$ away. The macroseismic data Davison had access to were very good, but he had a firm belief that this earthquake must share a common epicentre with the Hereford earthquake of 17 December 1896.

As well as the question posed by Cecic et al. (1996) there is the question as to whether epicentres from macroseismic data agree with instrumental epicentres where these are welldetermined. In most cases for U.K. earthquakes where instrumental epicentres are accurate to within a few kilometres, the agreement with the macroseismic epicentres, independently determined, is very good. There are, however, exceptions, the two most prominent being the 
Nottingham earthquake of 30 May 1984 (fig. 1) and the Isle of Man earthquake of 9 November 1987 (fig. 2). In both cases the magnitudes are relatively small and the depths are over $15 \mathrm{~km}$, which may contribute to the problem. The Isle of Man example is a difficult case anyway, on account of the land-sea distribution. A small earthquake on 1 January 1994 occurred in the middle of the Bristol Channel, but was felt only inland in North Devon (fig. 3). This casts doubt on the epicentral location of some previous events in this area, e.g. the earthquake of 2 April 1769 in North Devon.

\section{Depth}

The determination of depth from macroseismic data is not straightforward, and is best attempted where the macroseismic data is sufficiently good to allow at least three isoseismals to be drawn. The technique used is based on the formalism attributed to Kövesligethy (1907), developed by Sponheuer (1960), and which has since been used widely in Europe (Karnik, 1969). The version of the formalism as given by Burton et al. (1985) is as follows:

$$
I_{0}-I_{i}=3 \log \left(r_{i} / h\right)+3 \alpha M\left(r_{i}-h\right)
$$
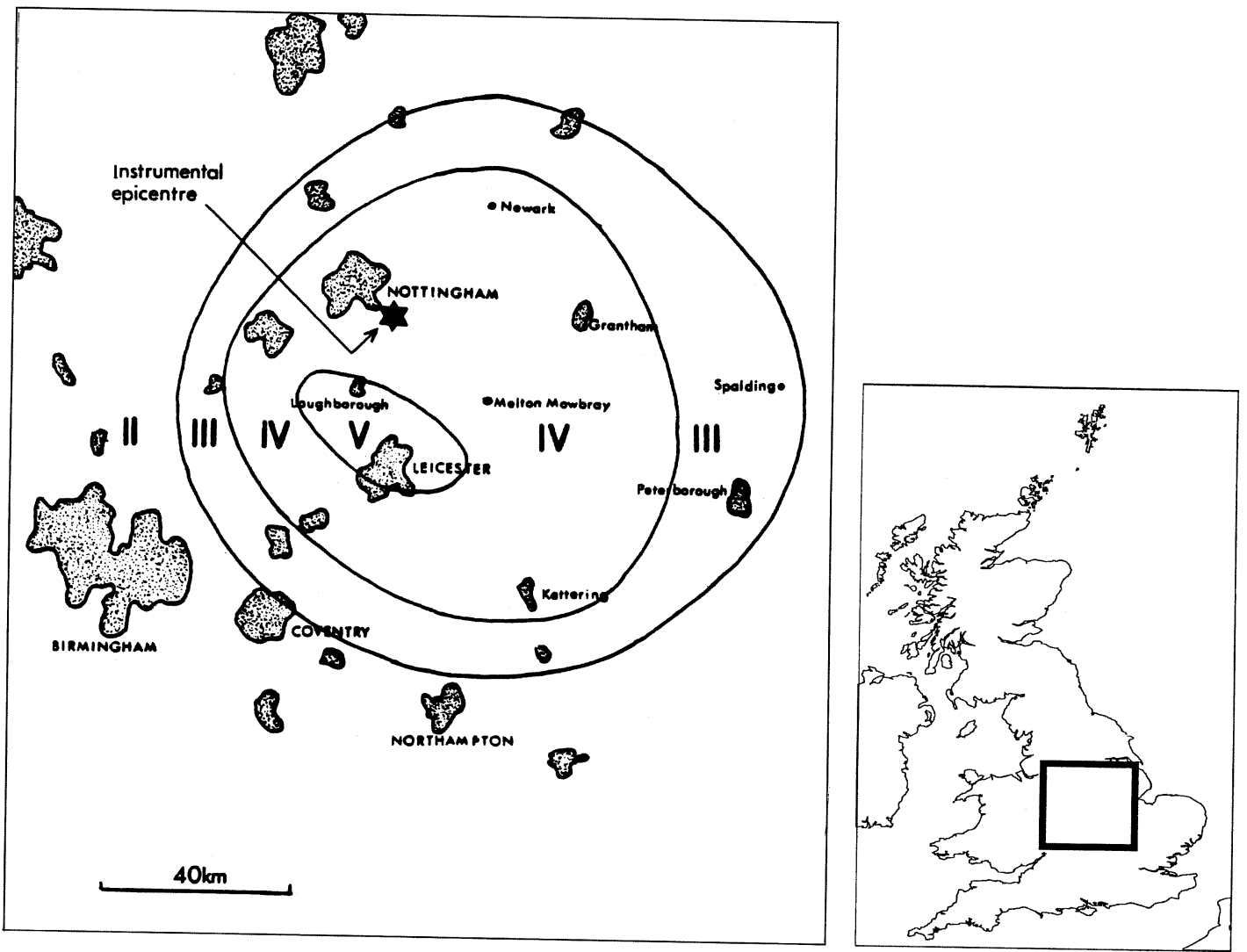

Fig. 1. The 30 May 1984 Nottingham earthquake - the macroseismic epicentre is on the NW outskirts of Leicester (taking the centre of the highest isoseismal) or at Melton Mowbray (centre of felt area), and in either case distant from the instrumental epicentre. Some historical earthquakes in this area share macroseismic epicentres with the 1984 event - where would their instrumental epicentres have been? (Taken from Marrow,
1984). 

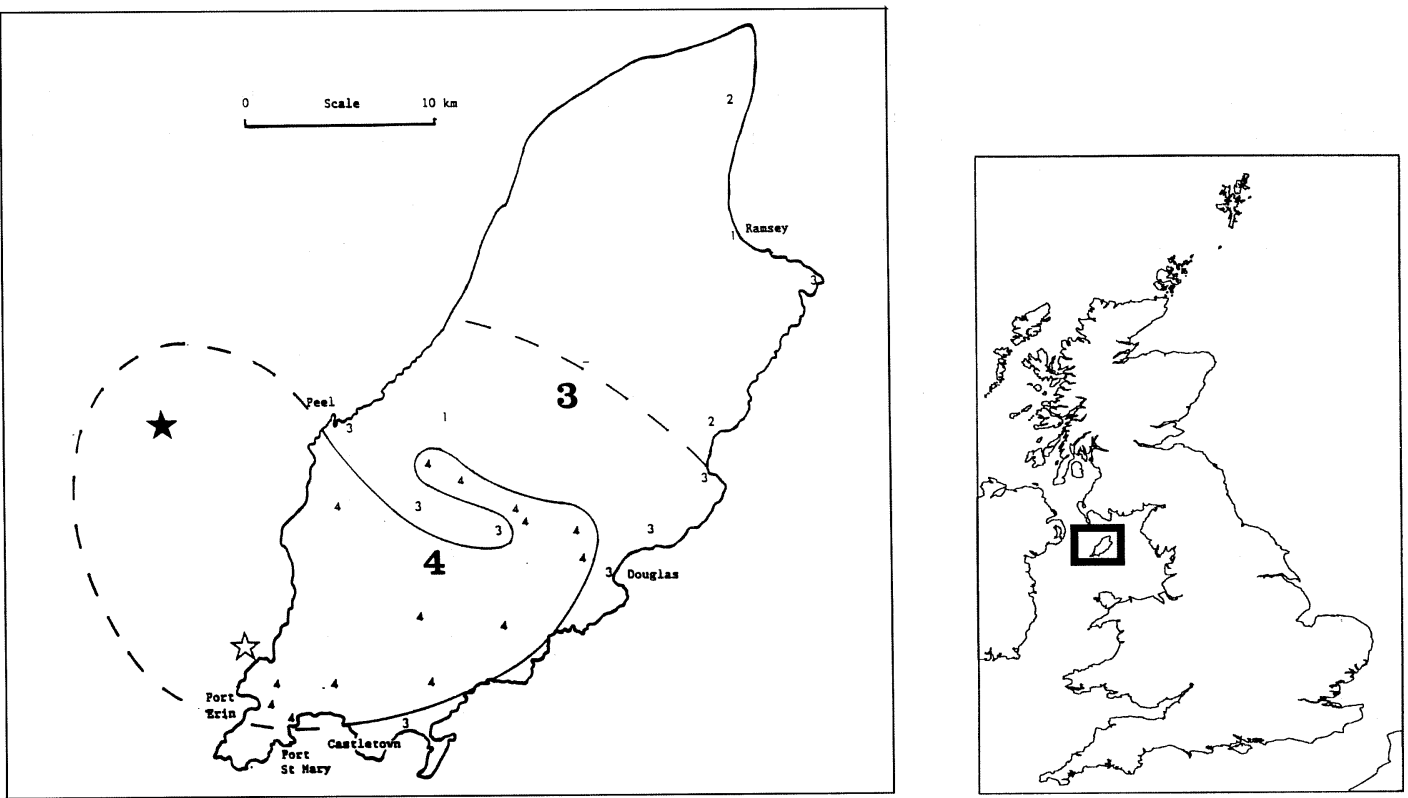

Fig. 2. The 9 November 1987 Isle of Man earthquake, showing the instrumental epicentre (black star; accurate) and the macroseismic epicentre (white star; not so well-determined) and a very tentative effort to reconcile the instrumental epicentre with the isoseismals (taken from Musson et al., 1988).
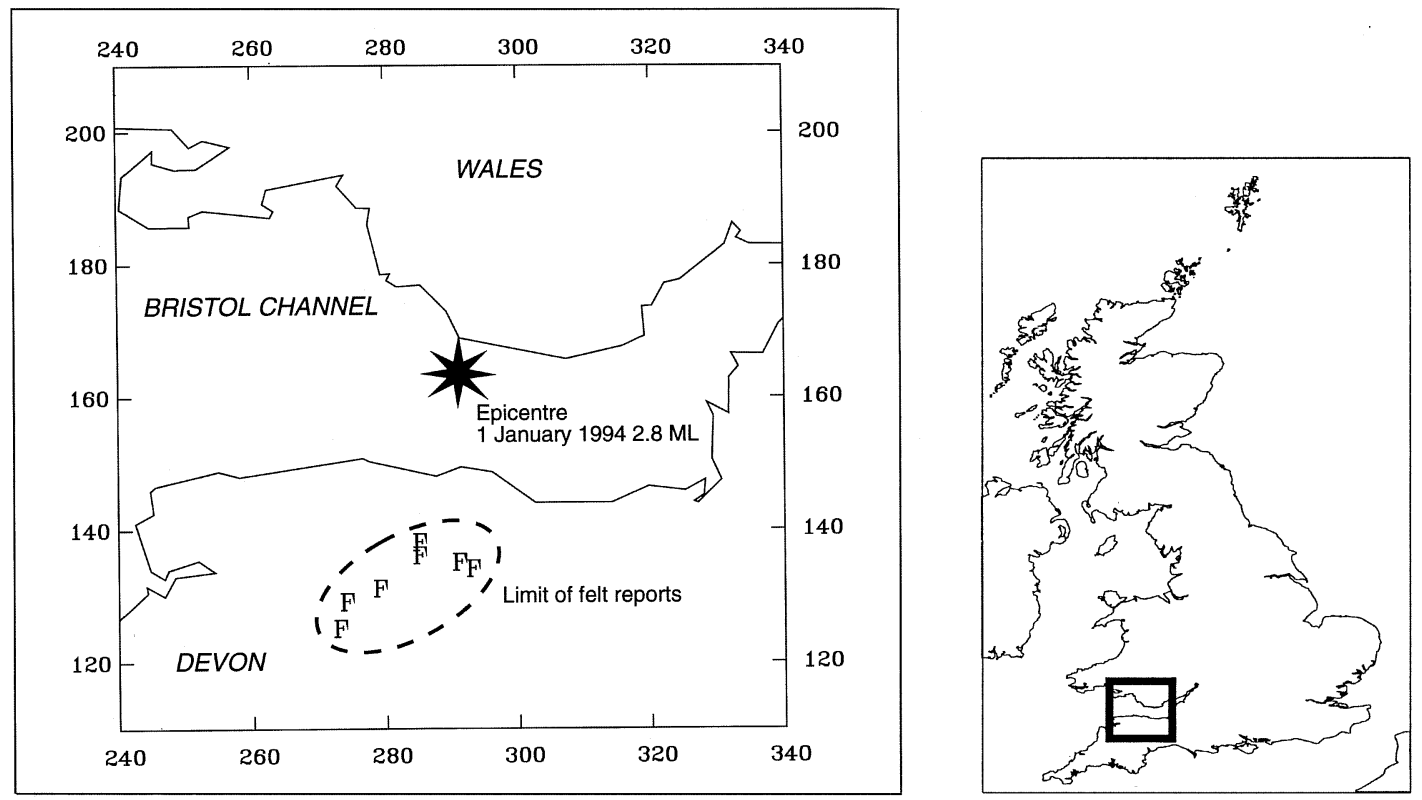

Fig. 3. The 1 January 1994 Bristol Channel earthquake. The margin figures are British National Grid co-ordinates in kilometres, which also provide the scale. 
where $I_{0}$ is the epicentral intensity, $I_{i}$ is the intensity at any isoseismal $i, r_{i}$ is the hypocentral (not epicentral) distance to the isoseismal $i$ in $\mathrm{km}, h$ is the depth in $\mathrm{km}$, and $M$ and $\alpha$ are both constants. $M$ is equal to $\log e$, while $\alpha$ is the «attenuation constant».

The original Kövesligethy (1907) equation was simply

$$
I-I_{0}=3 \log \sin e
$$

where $e$ is the angle of emergence.

In solving the Sponheuer formalism, $I_{0}$ and $h$ must both be treated as unknowns. The reason for treating $I_{0}$ as an unknown is twofold; firstly the formalism requires intensity to be considered as a real variable whereas it is properly an integer variable; secondly there may be uncertainty in the $I_{0}$ for some earth- quakes, especially where the epicentre is offshore or in an unpopulated area.

The value of the attenuation coefficient $\alpha$ is believed to vary regionally. It was assessed by a group optimisation of 111 earthquakes for which there were adequate isoseismal data (i.e., at least three isoseismals). The resulting value of $\alpha$ was 0.003 .

The formalism was then solved for each earthquake for a range of values for $I_{0}$ and $h$; values of $I_{0}$ from the intensity of the innermost isoseismal to that value plus three (in steps of 0.1 of an intensity value) were tested, and values of $h$ from 1 to $50 \mathrm{~km}$ (in steps of $1 \mathrm{~km}$ ). For any test values of $I_{0}$ and $h$, the formalism can be used to predict intensity values at each isoseismal radius, and these predicted values can be compared to the observed values. By squaring each difference, summing and taking

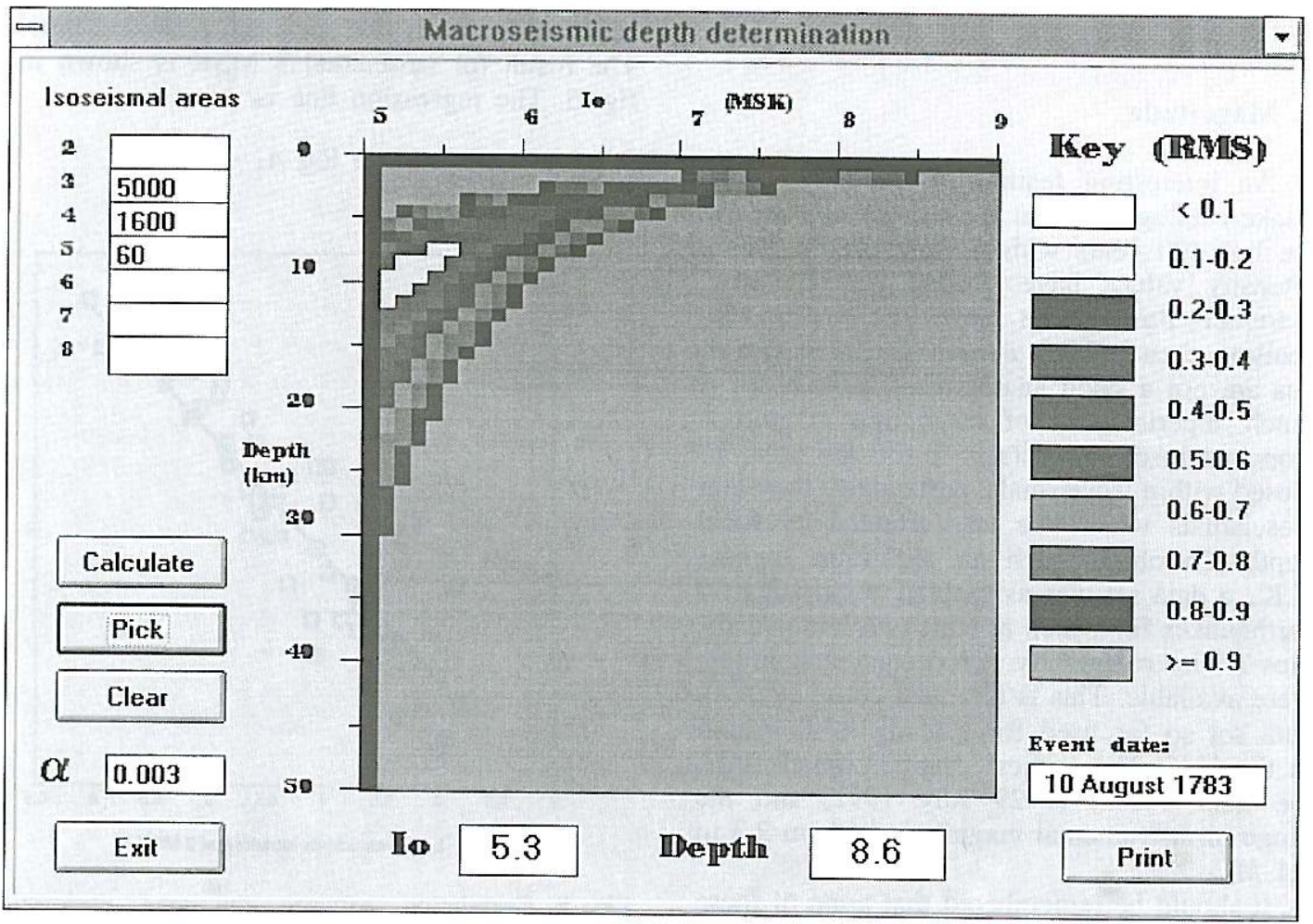

Fig. 4. Output from the MACDEP program for the 10 August 1783 Launceston (Cornwall) earthquake. 
the mean for the whole isoseismal set, and taking the square root of the result a Root Mean Square (RMS) value can be obtained for each «solution» of the formalism. The variation of RMS with $I_{0}$ and $h$ forms a surface which can be represented graphically. It is then possible to determine $h$ by contouring the RMS values and making an «eyeball» assessment of the $I_{0}$ value that best corresponds with the centre of the lowest contour and is consistent with macroseismic observations, and reading off the corresponding $h$ value.

This was done using the program MACDEP for PC running MS Windows. A sample screen from MACDEP is shown as fig. 4.

To assess the accuracy of the method, a comparison was done of macroseismic depths to modern instrumental depths for those earthquakes where both were possible. The mean value of $h$ (instrumental) minus $h$ (macroseismic) is $1.55 \mathrm{~km}$ and the median error is $0 \mathrm{~km}$. This suggests that there is no systematic error.

\section{Magnitude}

An interesting feature of the U.K. earthquake catalogue is that the two earthquakes in the last 400 years with the highest maximum intensity values have limited (in one case, extremely limited) felt areas. These were very shallow events. They demonstrate that $I_{0}$ values are not a good analogue of magnitude. A much superior way of estimating magnitude from macroseismic data is to use the area enclosed within isoseismals, particularly the outer isoseismals which are less affected by focal depth. To obtain such an algorithm for the U.K., a data set was assembled comprising 50 earthquakes for which at least two isoseismals, plus an instrumentally determined magnitude, were available. This is the most complete such data set so far used for a study of this kind in the U.K. The earliest event is dated 1903, the most recent is 29 July 1992, and the range in instrumental magnitude is from 2.3 to $6.1 M_{L}$.

It should be remembered that none of these figures are very exact, and this puts a limit on the degree of sophistication that can meaning- fully be employed. Magnitudes themselves are a notoriously unreliable statistic. In the case of recent BGS magnitudes, the usual rule of thumb is to regard the quoted values as being $\pm 0.2 M_{L}$ (Turbitt, personal communication). For earlier events, particularly very early events where the quoted magnitude is derived from few stations, it is evident that the accuracy is going to be poorer.

The same is true to a lesser extent with the felt area calculations, where incomplete data, subjective judgement, and extrapolation of areas out to sea or into areas with no data combine to give rather noisy data. However, since calculations are performed with the base ten logarithm of the felt area, relatively minor differences of interpretation are greatly reduced in significance once the logarithm has been taken.

This noisiness of the data makes any attempt at elaborate modelling inappropriate. A simple linear regression against logarithm of isoseismal area is the approach followed here. The result for isoseismal $3 \mathrm{MSK}$ is shown in fig. 5. The regression line is:

$$
M_{L}=1.03 \log A_{3}-0.19
$$

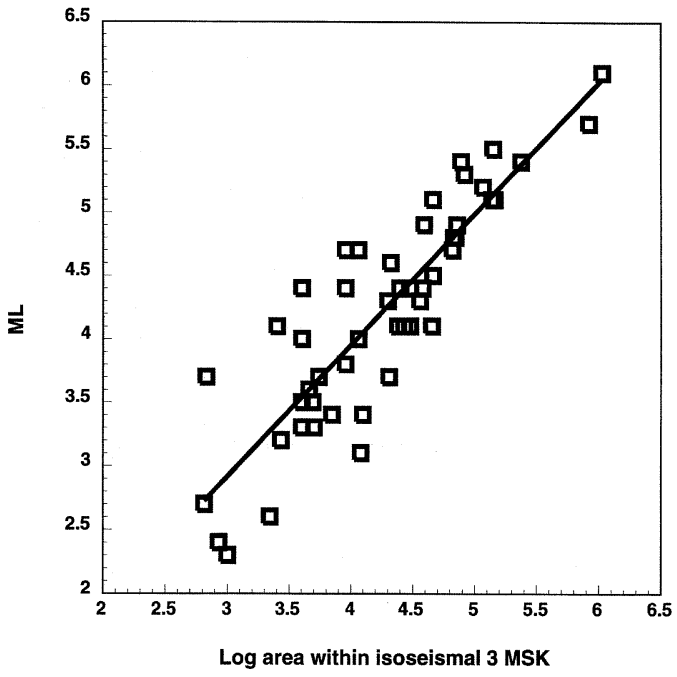

Fig. 5. Correlation between the area enclosed within isoseismal $3 \mathrm{MSK}$ and instrumentally-determined local magnitude $\left(M_{L}\right)$ for the U.K. 
for isoseismal $3 \mathrm{MSK}$, and

$$
M_{L}=0.92 \log A_{4}+0.71
$$

for isoseismal 4 MSK.

The comparison of macroseismic magnitudes predicted from isoseismal 3 with those from isoseismal 4 is a practical test of the reliability of the method; both regressions ought to give the same answers. The results were compared and found to be in good agreement. The mean absolute difference is 0.15 , which is less than the uncertainty in instrumental magnitude values.

In calculating magnitude values for the British earthquake catalogue, the regression using isoseismal 3 MSK was generally used. Where a felt area was known, but no isoseismals could be drawn, it was generally assumed that the felt area corresponded with isoseismal 3 MSK.

\section{Conclusions}

Using the techniques described above it has been possible to assemble a catalogue of British earthquakes with consistently-assessed parameters stretching back 300 years. Earlier events are included, but, from familiarity with the historical and geographical constraints, it may be estimated that the catalogue begins to be complete from around 1700. Since the British Isles are in a zone of low to moderate seismicity, a catalogue of this length is important if issues of seismic hazard are to addressed adequately. Instrumental data alone are insufficient to depict British seismicity, and it is the use of macroseismic data that enables location, magnitude and depth to be estimated for earlier earthquakes. It is hoped that the methods and results presented here may also be of use in other countries of similar tectonic characteristics.

\section{Acknowledgements}

The preparation of this report was supported by the Natural Environment Research Council and it is published with the approval of the Director of the British Geological Survey (NERC).

\section{REFERENCES}

Ambraseys, N.N. and C. Melville (1983): The Seismicity of the British Isles and the North Sea, SERC Marine Technology Centre, London.

Burton, P.W., R. MCGonigle, G. NeILson and R.M.W MUSSON (1985): Macroseismic focal depth and intensity attenuation for British earthquakes, in Earthquake Engineering in Britain (Telford, London), 91-110.

Cecié, I., R.M.W. Musson and M. STUCCHI (1996): Do seismologists agree upon epicentre determination from macroseismic data?, Annali di Geofisica, 39, 10131027 (this volume).

CHENEY, C.R. (1970): Handbook of Dates for Students of English History, Offices of the Royal Hist. Soc., London.

Davison, C. (1926): The Hereford earthquake of 15th August, 1926, Geol. Mag., 64, 162-167.

Guidoboni, E. (1983): 3 Janvier 1117: le tremblement de terre du moyen age Roman, aspects des sources, in Actes du Colloque, IVèmes Rencontres Internationales d'Archéologie et d'Histoire d'Antibes, 119-139.

KARNIK, V. (1969): Seismicity of the European Area (Reidel, Dordrecht).

KÖVESLIGETHY, R. VON (1907): Seismicher starkegrad und intensitat der beben, Gerlands Beitr. Geophys., 8, 363-366.

Marrow, P.C. (1984): The magnitude 3.1 earthquake in the East Midlands on 30 May 1984, BGS Global Seismology Report, No. 240.

Musson, R.M.W. (1994): A catalogue of British earthquakes, BGS Technical Report, No. WL/94/04.

Musson, R.M.W., M.A.E. RITCHIE and I. InNES (1988): The Isle of Man earthquake of 9 November 1987, BGS Global Seismology Report, No. WL/88/9.

SPONHEUER, W. (1960): Methoden zur Herdtiefenbestimmung in der Makroseismik (Freiberger Forschungshefte C88, Akademie Verlag, Berlin). 